\title{
Induced pluripotent stem cells: opportunities and challenges
}

\section{"Although a new field by any measure, we feel that the future of cellular reprogramming in general and iPS cells in particular is a rosy one."}

When we were invited to guest edit this special issue of Regenerative Medicine dedicated to induced pluripotent stem (iPS) cells, it was simultaneously an honor, an opportunity and a challenge. The opportunity stemmed from being able to invite and read state-of-the-art reviews, commentaries and reports from leaders in the field; a group of authors including those hailing from academia and the private sector alike. If this new technology has any hope of improving medical practice, and there are a variety of ways this might happen as highlighted in this issue of the journal, then the cooperative interplay between basic research institutions, biotech and pharmaceutical companies must be encouraged. The journal's invitation for the two of us to guest edit this issue together embodies that very spirit and we have been delighted to participate.

The challenge of shouldering the task of reviewing the iPS cell field is that it is advancing at such an astonishing rate. When we began, we did so knowing that many cellular reprogramming-related scientific breakthroughs would likely be made as we worked to finalize this issue. Our only hope was that none would make obsolete the views presented herein before they could be published. The pace of discovery in the field of cellular reprogramming following Shinya Yamanaka's first report at the International Society for Stem Cell Research's annual meeting in Toronto, Canada (2006) has been nothing short of breathtaking [1]. Never before have we witnessed the rapidity with which findings have been duplicated and incremental advances made to refine a methodology. Today finds any number of investigators worldwide able to direct the reprogramming of somatic cells to pluripotency, using cells obtained from a wide variety of anatomical sources and species, and all manipulated with relative ease. This was an unthinkable task 5 years ago where practitioners of nuclear transfer perhaps stood alone in the hope that such technology might one day be a practical tool to study disease, generate large numbers of defined cell types for use in screening platforms and, that ultimate objective, create patient-matched cells and tissues for clinical transplantation. Among other goals, the cutting edge of today's work aims to understand the genetic and epigenetic regulation of the reprogramming process, to improve the efficiency of iPS cell generation, and do so in a manner that creates cells with minimal or no genomic alteration. Given both the current tempo of work within the field as well as the sheer number of laboratories interested in iPS cell technology, we do not expect the attainment of these goals to be long in coming.

What iPS cells have already done for the fields of developmental biology and regenerative medicine is impossible to tally accurately let alone considering what further impact they may have. What is clear is that we are living through a revolution in our understanding of cellular lineage specification, tissue genesis and the epigenetic regulation of our genome, and all because of the availability of iPS cells and the reprogramming process. The field as a whole is composed of several parts and this issue seeks to shed light on many of them. In-Hyun Park from Yale (CT, USA) and Peter Gaines from the University of Massachusetts (MA, USA) provide some recent research highlights [2]. Other topics include refinement of the basic technology, where John Dimos from iPierian, Inc. (CA, USA) provides a thoughtful editorial [3] and iPierian's John Walker is interviewed regarding his forecast for the days to come [4]. They are joined herein by Linzhao Cheng from Johns Hopkins University (MD, UDA) writing on postnatal sources of cells for use in reprogramming [5], Guoping Fan of the University of California, Los Angeles (CA, USA) on the subject of epigenetics [6], Uma Lakshmipathy

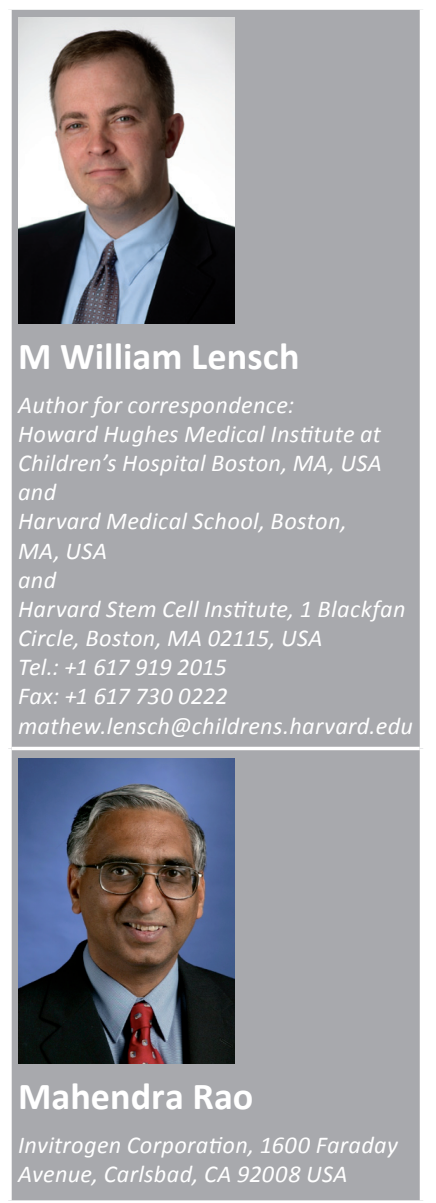

future medicine $^{\text {pard }}$ fs 
from Invitrogen (CA, USA) together with Ron Hart from Rutgers University (NJ, USA) on the topic of miRNA [7] and Michael West of BioTime, Inc. (CA, USA), who provides insights into some of the quality control issues inherent to cellular therapeutics [8]. The use of iPS cell technology in drug screening is tackled by Jessica Yingling of Fate Therapeutics (CA, USA) [9] and toxicology applications are put into perspective by Pfizer's (MA, USA) John McNeish [10].

When building our 'wish list' of topics and writers, we felt that it was equally important that we hear from experts beyond the bench and we are most pleased to also have reports and commentaries from Jane Love at WilmerHale (NY, USA) addressing intellectual property [11], Melissa Carpenter at Novocell (CA, USA) on regulatory issues [12] and Devyn Smith from Pfizer on iPS cellular therapies as a business model [13]. Finally, Marie Csetse, former Chief Scientific Offer at the California Institute for Regenerative Medicine (CA, USA) reviews the hopes and pitfalls in the clinical application of iPS cells [14].
In closing, we hope that this special issue of Regenerative Medicine provides food for thought in your own work whether within the cellular reprogramming field or elsewhere. We are sincerely grateful for the time that each of our contributors dedicated to sharing their insights, experience and predictions and to Chris Mason, Elisa Manzotti and Charlotte Barker from Regenerative Medicine for the invitation to guest edit this issue. Although a new field by any measure, we feel that the future of cellular reprogramming in general and iPS cells in particular is a rosy one. We look forward to the breakthroughs to come and wish you well in your own research.

\section{Financial \& competing interests disclosure}

$M$ Rao is an employee of Invitrogen Corporation. The authors have no other relevant affiliations or financial involvement with any organization or entity with a financial interest in or financial conflict with the subject matter or materials discussed in the manuscript apart from those disclosed.

No writing assistance was utilized in the production of this manuscript.

\section{Bibliography}

1 Yamanaka S: Identification of factors that generate ES-like pluripotent cells from fibroblast culture. Presented at: 4 th International Society for Stem Cell Research. Ontario, Canada, 29 June-1 July (2006).

2 Gaines P, Liu R, Park I-H: Research Highlights. Regen. Med. 5(4), 501-503 (2010).

3 Grskovic M, Seidenman K, Dimos JT: Cell programming: jumping back to pluripotency or rewiring fate. Regen. Med. 5(4), 493-495 (2010).

4 Walker J: Disease in a dish: a new approach to drug discovery. Regen. Med. 5(4), 505-507 (2010).

5 Ye Z, Cheng L: Potential of human induced pluripotent stem cells derived from blood and other postnatal cell types. Regen. Med. 5(4), 521-530 (2010).
6 Huang K, Fan G: DNA methylation in cell differentiation and reprogramming: an emerging systematic view. Regen. Med. 5(4), 531-544 (2010).

7 Lakshmipathy U, Davila J, Hart RP: miRNA in pluripotent stem cells. Regen. Med. 5(4), 545-555 (2010).

8 West MD, Homayoun V: Back to immortality: the restoration of embryonic telomere length during induced pluripotency. Regen. Med. 5(4), 485-488 (2010).

9 Flynn P, Yingling J, Shoemaker D: Converging technologies to enable induced pluripotent stem cells in drug discovery. Regen. Med. 5(4), 489-491 (2010).

10 Rowntree RK, McNeish JD: Induced pluripotent stem cells: opportunities as research and development tools in 21st century drug discovery. Regen. Med. 5(4), 557-568 (2010).
11 Georgieva BP, Love JM: Human induced pluripotent stem cells: review of the US patent landscape. Regen. Med. 5(4), 581-591 (2010).

12 Carpenter MK, Couture LA: Regulatory considerations for the development of autologous iPS cell therapies. Regen. Med. 5(4), 569-579 (2010).

13 Smith D: Commercialization challenges associated with induced pluripotent stem cell-based products. Regen. Med. 5(4), 593-603 (2010).

14 Csete M: Translational prospects for human induced pluripotent stem cells. Regen. Med. 5(4), 509-519 (2010). 